\title{
Effect of the neuropathic pain receptor P2X3 on bladder function induced by intraperitoneal injection of cyclophosphamide (CYP) in interstitial cystitis rats
}

\author{
Lei Pang ${ }^{1,2}$, Jinkai Shao ${ }^{2}$, Xiaodong Wen ${ }^{2}$, Dong Liu ${ }^{2}$ Zhijia Zhang ${ }^{2}$, Weibing Shuang ${ }^{3}$ \\ ${ }^{1}$ Department of Graduate, Shanxi Medical University, Taiyuan, China; ${ }^{2}$ Department of Urology, Fifth Affiliated Hospital of Shanxi Medical \\ University, Taiyuan, China; ${ }^{3}$ Department of Urology, First Affiliated Hospital of Shanxi Medical University, Taiyuan, China \\ Contributions: (I) Conception and design: L Pang; (II) Administrative support: W Shuang; (III) Provision of study materials or patients: J Shao; (IV) \\ Collection and assembly of data: Z Zhang; (V) Data analysis and interpretation: X Wen, J Shao; (VI) Manuscript writing: All authors; (VII) Final \\ approval of manuscript: All authors. \\ Correspondence to: Weibing Shuang. Department of Urology, First Affiliated Hospital of Shanxi Medical University, No. 85 Jiefang South Road, \\ Yingze District, Taiyuan 030001, China. Email: shuangweibing@126.com.
}

Background: The role of purinergic receptor $\mathrm{P} 2 \mathrm{X} 3$ in pathological bladder dysfunction and chronic pelvic pain remains unclear. We aim to investigate the effect of $\mathrm{P} 2 \mathrm{X} 3$ on bladder function in interstitial cystitis (IC) through the IC rat model induced by cyclophosphamide (CYP).

Methods: A total of 120 female Sprague-Dawley (SD) rats were randomly divided into 6 groups: control, CYP-4h, CYP-48h, CYP-10d, CYP-30d, and CYP-45d groups. The control group was injected with normal saline. The rats in the CYP-4h and CYP-48h groups were given a single high dose. The rats in the CYP10d, CYP-30d, and CYP-45d groups were given a low dose of CYP repeatedly every three days. Bladder voiding function was measured using urodynamic techniques to observe the effect of the P2X3 receptor on bladder function in CYP-induced IC.

Results: The rats in the CYP-4h group showed significant overactivity of the bladder compared with the control group, the bladder voiding interval was shortened $(\mathrm{P}<0.01)$, and the maximal voiding pressure was increased $(\mathrm{P}<0.01)$. At the same time, the degree of overactive bladder in the CYP-48h, CYP-10d, CYP-30d, and CYP-45d groups became increasingly serious, the interval of bladder micturition was shortened stepwise $(\mathrm{P}<0.01)$, and the maximal micturition pressure was increased stepwise $(\mathrm{P}<0.01)$. Compared with the control group, the CYP-48h group mainly showed a shorter bladder voiding interval $(\mathrm{P}<0.01)$, lower voiding volume, and higher activation of mast cells and inflammatory factors in the bladder. In the CYP-10d group, bladder mast cell activation and inflammatory factors increased significantly. Intrathecal injection (IT) of A-317491 significantly prolonged the bladder voiding intervals in CYP-4h, CYP-48h, CYP-10d, CYP-30d, and CYP$45 \mathrm{~d}$ rats $(\mathrm{P}<0.01)$, and the maximal voiding pressure of the CYP-4h, CYP-48h, CYP-10d, CYP-30d, and CYP-45d groups was significantly decreased $(\mathrm{P}<0.05)$, while the maximal voiding pressure of the CYP-10d group was not significantly affected.

Conclusions: P2X3 receptors in dorsal root ganglion (DRG) play an important role in bladder function induced by intraperitoneal injection of CYP in rats. IT of P2X3 inhibitors can significantly improve the grade of bladder voiding dysfunction and chronic pelvic pain.

Keywords: P2X3; interstitial cystitis (IC); overactive bladder; neuropathic pain

Submitted Dec 23, 2021. Accepted for publication Feb 16, 2022.

doi: $10.21037 /$ tau-22-23

View this article at: https://dx.doi.org/10.21037/tau-22-23 


\section{Introduction}

Interstitial cystitis bladder pain syndrome (IC/BPS) is a chronic and complex urological condition which the International Institute of Urology defines as "pelvic pain associated with bladder filling, accompanied by other symptoms such as increased frequency of daytime and nighttime urination, with the exception of urinary tract infections and other pathological changes" (1). Although the pathogenesis of the disease is not clear and there is no effective treatment, there is growing evidence that neurogenic cystitis and urinary tract epithelial dysfunction are important pathophysiological bases for the development of neurogenic symptoms (1). Bladder sensory information can be uploaded to the spinal cord via lumbar visceral nerve and pelvic nerve. The cell bodies of visceral sensory afferent pathways of lumbar visceral nerve and pelvic nerve are located in the dorsal root ganglion (DRG) of thoracolumbar (TL: T13-L2) and lumbosacral (LS: L6S2) (2), respectively. Studies have shown that, when the bladder epithelium is stretched, adenosine triphosphate, a neurotransmitter, is released by epithelial cells, which in turn activates purinergic receptors on bladder sensory nerve endings, transmits sensory signals to the crest of the medulla and higher visceral sensory centers, and regulates the voiding reflex (3).

Adenosine triphosphate (ATP) signaling pathway is involved in physiological micturition reflex and bladder dysfunction. A clinical study showed that ATP release from bladder urothelial cells was increased in patients with IC/ BPS, suggesting that IC/BPS is related to abnormal ATP signaling pathways (4). In bladder sensory neurons, P2X2, $\mathrm{P} 2 \mathrm{X} 2 / 3$, and $\mathrm{P} 2 \mathrm{X} 3$ receptors are the main purinergic receptors that respond to ATP, but the mechanism is still unclear. Other studies have found that cyclophosphamide can be metabolized in the body as acrolein, which breaks down the mucosal barrier of the bladder epithelium and irritates the bladder tissue. This irritation was found to lead to cystitis in humans, rats, and mice, and caused frequent and urgent micturition, additional injury to the bladder function barrier, and pelvic cavity ache (4). It is reported that cyclophosphamide-induced bladder inflammation sensitizes and increases $\mathrm{P} 2 \mathrm{X}$ receptor expression and function for both pelvic and lumbar splanchnic pathways, which is related to the hypersensitivity associated with cystitis (5). Previous research used an intraperitoneal injection of cyclophosphamide (CYP) into rats and mice, using the IC/ BPS animal model (2). These studies showed that $100 \mathrm{mg} / \mathrm{kg}$ of CYP continuously injected intraperitoneally can cause pathological changes in mouse bladder tissue and can also cause changes in the function of $\mathrm{P} 2 \mathrm{X} 2$ and $\mathrm{P} 2 \mathrm{X} 3$ receptors in LS and TL bladder sensory neurons $(6,7)$.

In clinic practice, most patients with IC/BPS presented with voiding dysfunction and pelvic pain, however, there is no significant organic pathological change in the bladder tissue, indicating the presence of abnormal excitability of sensory neurons in the IC/BPS patients. Till now, the underlying mechanism of abnormal excitability of sensory neurons and the function of $\mathrm{P} 2 \mathrm{X}$ receptors in CYP mice without organic pathological changes remains elusive.

In this study, we established a cytoxan-induced IC model in rats and observed the effects of IC on bladder morphology and micturition function. The purpose of this was to explore the role of the P2X3 receptor in DRG in ICinduced bladder dysfunction and chronic pelvic pain and to explore the role of the neuropathic pain receptor $\mathrm{P} 2 \mathrm{X} 3$ in IC bladder function. We present the following article in accordance with the ARRIVE reporting checklist (available at https://tau.amegroups.com/article/view/10.21037/tau$22-23 / \mathrm{rc})$.

\section{Methods}

\section{Laboratory animals and model establishment}

Animal experiments were performed under a project license [No. SCXK (Jin), 2020-0001] granted by the ethics committee of First Affiliated Hospital of Shanxi Medical University, in compliance with guidelines of Shanxi Medical University for the care and use of animals. A total of 120 healthy female Sprague-Dawley (SD) rats, aged from 6 to 8 weeks, with a body weight of $(250 \pm 20) \mathrm{g}$ were reared in Animal Laboratory of Shanxi Provincial People's Hospital and were in good health. The controlled temperature environment, animal testing process, and operation were in line with the requirements of the Shanxi Medical University (8). According to existing literature, a rat IC model was established by an intraperitoneal injection of CYP. Female SD rats were randomly divided into the following 6 groups: control, CYP-4h, CYP48h, CYP-10d, CYP-30d, and CYP-45d groups. The dosages and time courses were based on previous studies demonstrating CYP induction (9-11). The rats in the CYP4h and CYP-48h groups were given a single high-dose intraperitoneal injection of cyclophosphamide $(150 \mathrm{mg} / \mathrm{kg}$, intraperitoneally) under ether anesthesia for 24 hours, 
while the CYP-10d, CYP-30, and CYP-45 groups were given a low dose of CYP $(75 \mathrm{mg} / \mathrm{kg}$, intraperitoneal) repeatedly every three days. The control group was injected with $150 \mathrm{mg} / \mathrm{kg}$ of normal saline.

\section{Bladder histological examination}

\section{tissue sampling and staining}

The rats were euthanized on the next day after the injection administration and the samples were taken After the rats were anesthetized with $10 \%$ chloral hydrate ( $3 \mathrm{~mL} / \mathrm{kg}$ ), their hearts were punctured to obtain blood and serum, their lower abdomen was cut open, their bladder tissues were taken, and their bladders were fixed in $4 \%$ paraformaldehyde. Fixed paraffin was embedded, and the tissues were then cut into $5 \mu \mathrm{m}$ sections. Hematoxylin-eosin staining (HE) staining and toluidine blue staining were carried out after paraffin section dewaxing (12).

\section{Urodynamic study}

CYP was injected intraperitoneally for 4 hours, 48 hours, 10 days, 30 days, and 45 days to measure bladder pressure and observe the expression profile in an overactive bladder. After the rats were anesthetized with urethane intraperitoneally, a $1 \mathrm{~cm}$ incision was made in the lower abdomen to expose the bladder $(13,14)$. Then, a PE50 catheter was inserted $0.5-1.0 \mathrm{~cm}$ into the bladder cavity after a small incision was made on the top of the bladder with microscissors. After surgery, the other end of the PE50 catheter was connected to a microinjection pump (Avi 270, Smiths Medical, USA) and a pressure sensor (Chengdu Instrument Factory, Chengdu, China) via a three-way valve. The signal of the pressure sensor was collected and recorded by a multichannel signal processing system (Chengdu Instrument Factory). Normal saline was continuously infused into the bladder at a rate of $10 \mathrm{~mL} / \mathrm{h}$, and the changes in intravesical pressure were recorded. Finally, the intercontractile interval (ICI) and maximum bladder pressure (MBP) were analyzed (15).

\section{Intrathecal injection (IT)}

After the rats were anesthetized with isoflurane, the hair on the back of the rats was shaved, and an incision of approximately $2 \mathrm{~cm}$ was made along the midline of the dorsal skin above the L4-L5 lumbar spine. The dorsal ligaments and muscles were carefully dissected after exposing the
L4 and L5 spinous processes. The spinous processes and the intervertebral ligaments were then carefully dissected. Then, a 20-gauge needle was used to puncture the subdural space of rats in the L4-L5 intervertebral space, an ultrathin polyethylene catheter $(0.25 \mathrm{~mm}$ outside diameter) was slowly inserted into the subdural space, and the tip of the catheter was placed at L6-S1 in the rat (16). A slight tail flick or lower limb movement of the rat indicated that the catheter was placed in the correct position. Finally, the catheter was fixed to the surrounding muscles and ligaments, and the incision was closed. The P2X3 inhibitor A-317491 (10 g) was injected into the subdural space of the rat through the other end of the catheter.

\section{Statistical analysis}

Using SPSS 20.0 statistical software (IBM SPSS Inc., Chicago, USA), the data were expressed as $\bar{x} \pm \mathrm{s}$, and the 6 groups were compared with a Student's $t$-test, before and after the use of paired $t$-tests, with a significance level of 0.05 .

\section{Results}

\section{Bladder historical examination results}

Compared with the control group, the CYP-4h and CYP$48 \mathrm{~h}$ groups showed no significant differences in bladder HE staining results, while the bladders of the CYP-10d, CYP30d, and CYP-45d groups showed mucosal hyperemia, edema, wall thickening, and high levels of inflammatory cell infiltration (17). The results of toluidine blue staining showed that the infiltration levels of mast cells in the CYP10d, CYP-30d, and CYP-45d groups were significantly higher than those in the control group and the former two groups (Figure 1).

\section{Urodynamic study results}

The results of continuous cystometry indicated that CYP induced an overactive bladder in rats and increased the frequency of bladder micturition and the maximum micturition pressure. The bladder voiding interval of the CYP-4h group was $157.5 \pm 9.25 \mathrm{~s}$, which was shorter than that of the control group $(202.3 \pm 13.0 \mathrm{~s} ; \mathrm{P}>0.01)$. The bladder voiding interval in the CYP-48h group was $120.3 \pm 6.78 \mathrm{~s}$, which was significantly shorter than that in 

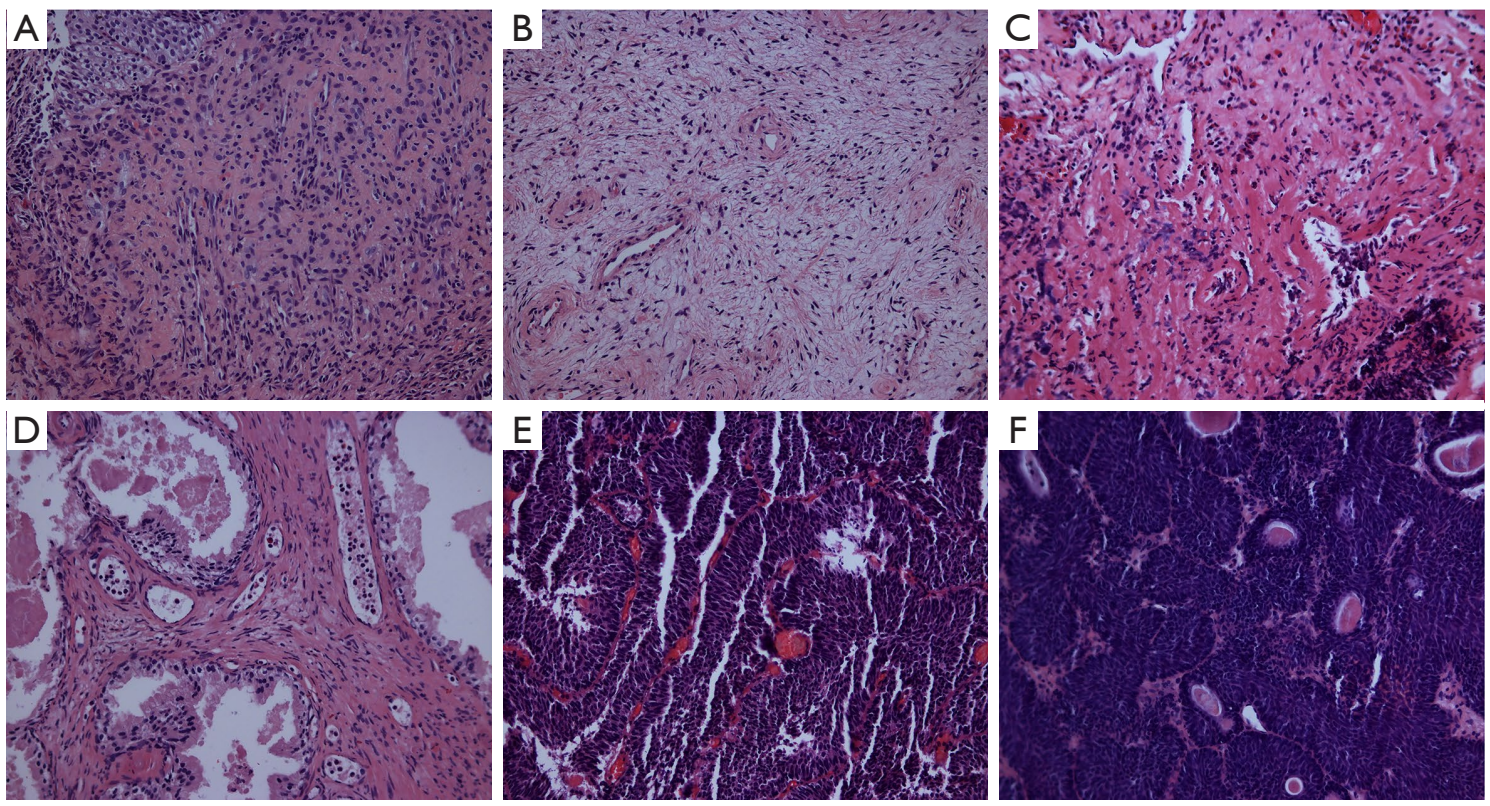

Figure 1 Histopathological changes in CYP-induced interstitial cystitis by HE staining. (A) Control group; (B) CYP-4h group; (C) CYP48h group; (D) CYP-10d group; (E) CYP-30d group; (F) CYP-45d group. Histopathological changes in the bladder were observed by HE staining. Histopathological changes of bladder in rats with CYP induced interstitial cystitis (10×40). CYP, cyclophosphamide; HE, hematoxylin-eosin staining. Magnification, $\times 200$.

Table 1 Bladder voiding interval and maximal voiding pressure after CYP injection in rats

\begin{tabular}{lcc}
\hline Group & Urination interval $(\mathrm{s})$ & $\begin{array}{c}\text { Maximum voiding } \\
\text { pressure }\left(\mathrm{cmH}_{2} \mathrm{O}\right)\end{array}$ \\
\hline Control group & $202.3 \pm 13.0$ & $30.0 \pm 8.11$ \\
CYP-4h & $157.5 \pm 9.25$ & $47.0 \pm 6.77$ \\
CYP-48h & $120.3 \pm 6.78$ & $62.8 \pm 7.52$ \\
CYP-10d & $70.0 \pm 4.29$ & $80.5 \pm 13.17$ \\
CYP-30d & $43.3 \pm 12.17$ & $106.8 \pm 16.96$ \\
CYP-45d & $12.3 \pm 5.72$ & $168.0 \pm 20.16$ \\
\hline
\end{tabular}

CYP, cyclophosphamide.

the control group $(202.3 \pm 13.0 \mathrm{~s} ; \mathrm{P}<0.01)$. The bladder voiding interval in the CYP-10d group was $70.0 \pm 4.29 \mathrm{~s}$, which was significantly shorter than that in the control group $(202.3 \pm 13.0 \mathrm{~s} ; \mathrm{P}<0.01)$. Compared with the control group, the maximal bladder voiding pressure in the CYP4h group was $47.0 \pm 6.77 \mathrm{cmH}_{2} \mathrm{O}$, which was significantly higher than that in the control group $\left(30.0 \pm 8.11 \mathrm{cmH}_{2} \mathrm{O}\right.$; $\mathrm{P}<0.01$ ) (18). Compared with the control group, the maximal bladder voiding pressure in the CYP-48h group was $62.8 \pm 7.52 \mathrm{cmH}_{2} \mathrm{O}$, which was significantly higher than that in the control group $\left(30.0 \pm 8.11 \mathrm{cmH}_{2} \mathrm{O} ; \mathrm{P}<0.01\right)$. The maximal bladder voiding pressure in the CYP-10d group was $80.5 \pm 13.17 \mathrm{cmH}_{2} \mathrm{O}$, which was significantly higher than that in the control group $\left(30.0 \pm 8.11 \mathrm{cmH}_{2} \mathrm{O}\right.$; $\mathrm{P}<0.01)$. Compared with that of the CYP-10d group, the maximal bladder voiding pressure of the CYP-30d group was significantly increased $\left(106.8 \pm 16.96 \mathrm{cmH}_{2} \mathrm{O}\right)$, which was significantly higher than that of the control group $(\mathrm{P}<0.01)$. Compared with the CYP-30d group, the CYP-

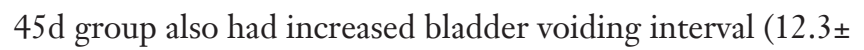
$5.72 \mathrm{~s})$, which was significantly higher than the control group $(\mathrm{P}<0.01)$ (Table 1, Figure 2$)$.

\section{The role of $\mathrm{P} 2 \mathrm{X} 3$ receptors in overactive bladder induced by IC}

The results of continuous bladder manometry showed that the overactivity of the bladder induced by IT of the P2X3 inhibitor A-317491 was significantly improved after In CYP-10d rats, an IT of A-317491 significantly prolonged the bladder voiding interval $(173.8 .7 \pm 22.35 \mathrm{~s}$; $\mathrm{P}<0.01)$ and decreased the maximal voiding pressure $(65.3 \pm$ 

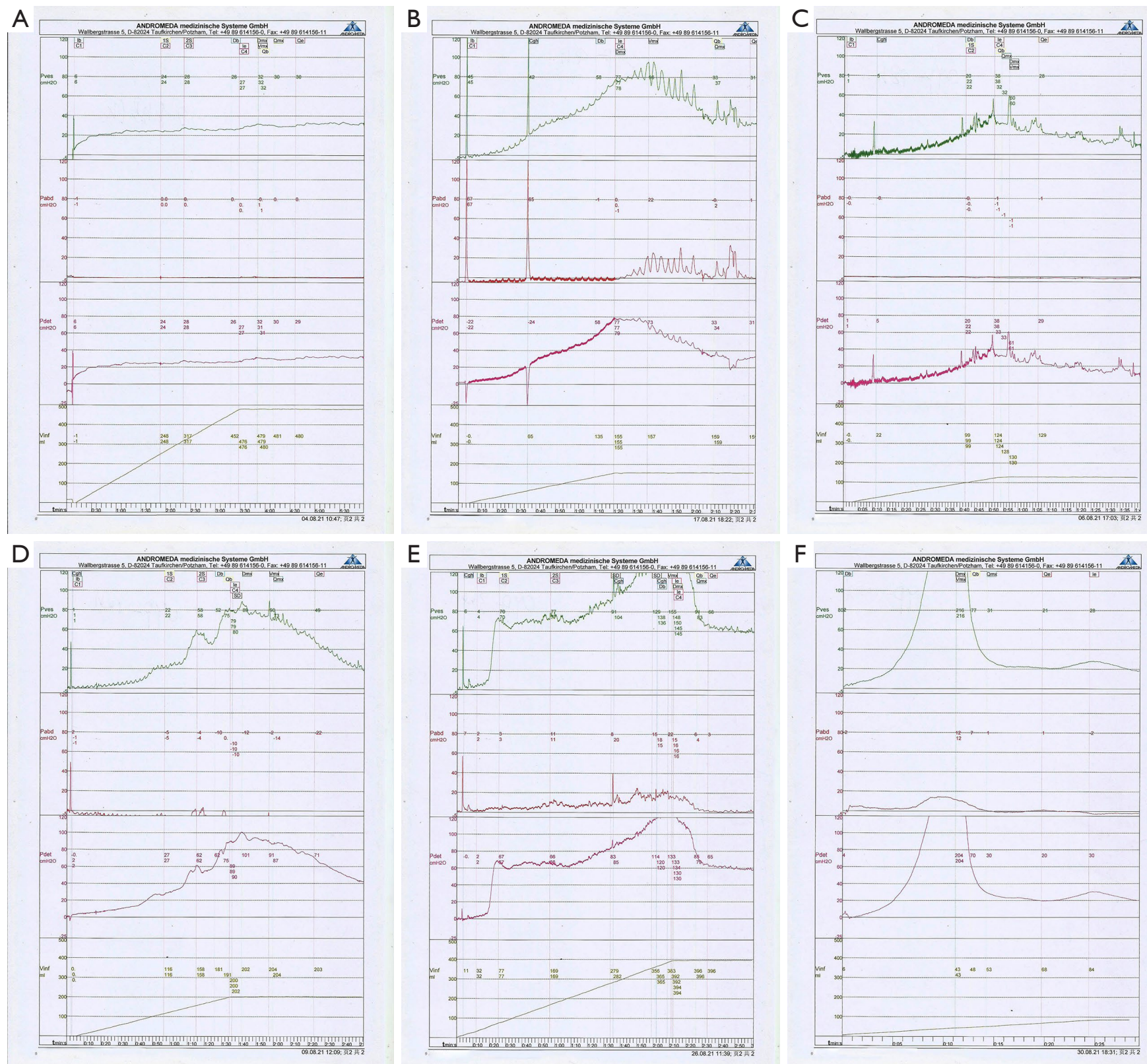

Figure 2 Effect of CYP-induced interstitial cystitis on urinary bladder function. (A) Control group; (B) CYP-4h group; (C) CYP-48h group; (D) CYP-10d group; (E) CYP-30d group; (F) CYP-45d group. Effect of CYP induced interstitial cystitis on bladder micturition function in rats. CYP, cyclophosphamide.

$\left.10.45 \mathrm{cmH}_{2} \mathrm{O} ; \mathrm{P}<0.01\right)$. In the CYP-30d and CYP-45d groups, the bladder micturition function of rats was almost normal after an IT of A-317491, the bladder micturition compartment was significantly prolonged $(75 \pm 17.99 \mathrm{~s}$; $\mathrm{P}<0.01)$, and there was no significant difference in maximal voiding pressure $\left(145.8 \pm 17.57 \mathrm{cmH}_{2} \mathrm{O}\right)$ (Table 2, Figure 3) (19).

\section{Discussion}

A growing body of clinical and animal evidence suggests that the bladder is controlled by the autonomic and central nervous systems, as well as by the DRG and the spinal cord (20). Thus, pathological states such as IC may cause initial sensitization of afferent fibers and sensory neurons 
around the bladder, which in turn may activate afferent nerves of the bladder through the crossing of the DRG or medullary ridges. Our study found that CYP-induced bladder IC did not significantly change the morphology of the bladder (We only observed inflammatory changes in the bladder) but showed symptoms of overactive bladder and increased urination frequency and voiding pressure (20). As IC recovered, overactivity in the bladder improved, but it did not return to normal. After CYP-induced IC for 10, 30, or more days, there was no significant difference between

Table 2 Bladder voiding intervals and maximal voiding pressure in rats after intrathecal injection

\begin{tabular}{lcc}
\hline Group & Urination interval $(\mathrm{s})$ & $\begin{array}{c}\text { Maximum voiding } \\
\text { pressure }\left(\mathrm{cmH}_{2} \mathrm{O}\right)\end{array}$ \\
\hline Control group & $202.3 \pm 13.0$ & $30.0 \pm 8.11$ \\
CYP-4h & $185.8 \pm 10.29$ & $40.0 \pm 9.32$ \\
CYP-48h & $190.3 \pm 28.45$ & $52 \pm 13.02$ \\
CYP-10d & $173.8 \pm 22.35$ & $65.3 \pm 10.45$ \\
CYP-30d & $106.3 \pm 26.50$ & $99.8 \pm 20.87$ \\
CYP-45d & $75 \pm 17.99$ & $145.8 \pm 17.57$ \\
\hline
\end{tabular}

CYP, cyclophosphamide. normal and overactive bladders, but overactive bladder was still present. Our study suggests that IC can have a profound and long-term effect on bladder function after the initial bladder irritation is gone, and this long-term effect may be related to IC sensitization of afferent nerves to the bladder.

Studies have shown that changes in the excitability and a variety of harmful substances properties of DRG neurons induced by IC play an important role in afferent neurosensitization of the bladder (20). IC can result in a decreased threshold of action potential and increased excitability of bladder-innervating DRG neurons. IC can also increase the expression levels of several nociceptive substances and receptors in DRG neurons, such as nerve growth factor (NGF), brain-derived neurotrophic factor, transient receptor potential vanilloid (TRPV1), neuropeptide calcitonin gene related peptide (CGRP), substance $\mathrm{P}$, and tyrosine kinase $\mathrm{B}(\operatorname{TrkB})(14,17)$. These nociceptive substances and receptors also play an important role in bladder overactivity caused by bladder inflammation. CYP-induced colitis in Trpv1 knockout mice showed marked improvements in bladder overactivity and pain sensitivity. Desensitization of transient receptor potential vanilloid by IT of resin toxin can reduce bladder
A

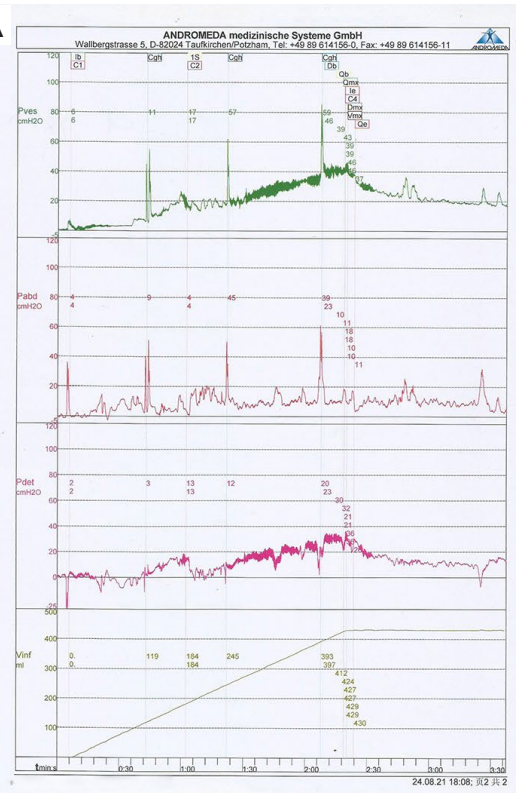

B

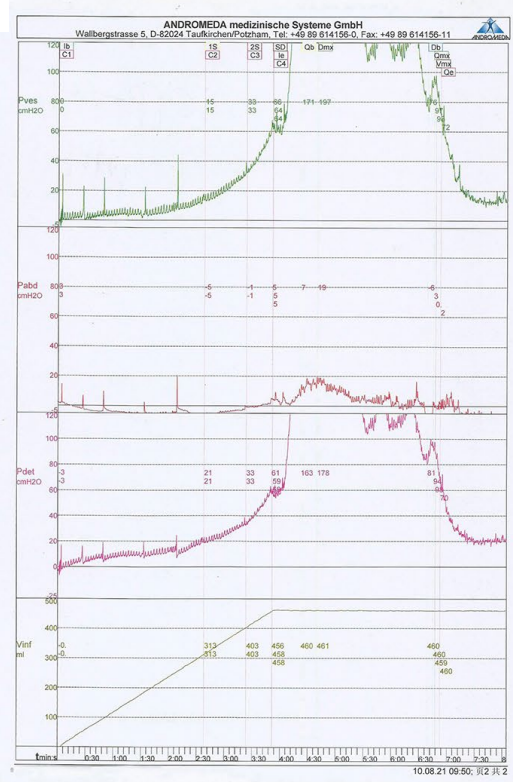

C

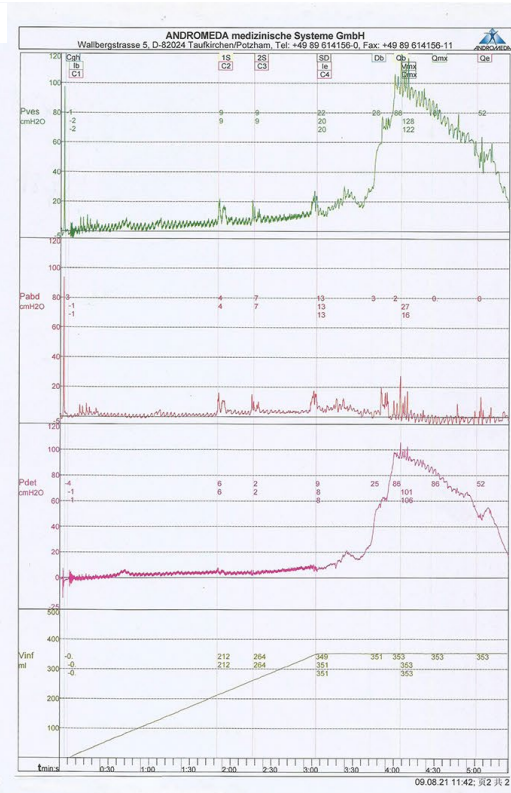

Figure 3 Role of the P2X3 receptor in bladder hyperactivity induced by interstitial cystitis. (A) A-317491 CYP-10d group; (B) A-317491 CYP-30d group; (C) A-317491 CYP-45d group. Effect of intrathecal injection on bladder function in rats with interstitial cystitis. CYP, cyclophosphamide. 
hyperactivity by reducing the expression of brain-derived neurotrophic factor (BDNF), substance P, and CGRP $(13,15,17)$. In addition, our study found that bladder mast cell infiltration increased significantly after CYP-induced IC. However, more studies are needed to confirm the relationship between increased mast cell infiltration and bladder afferent neurosensitization.

The P2X3 receptor is an ATP receptor expressed in primary sensory neurons and is involved in the regulation of ATP-mediated neuronal excitability. P2X3 receptors in primary sensory neurons have been shown to be involved in the transmission of multiple neuropathic pain as well as mechanosensory inputs to the bladder (21). The $\mathrm{P} 2 \mathrm{X} 3$ receptor is mainly expressed in sensory fibers and transitional epithelial cells in the bladder. When bladder epithelial cells were injured, the release of ATP increased, which acted on $\mathrm{P} 2 \mathrm{X} 3$ receptors of afferent nerve endings, activated $\mathrm{P} 2 \mathrm{X} 3$ receptors and promoted $\mathrm{P} 2 \mathrm{X} 3$ receptors to transfer to the cell membrane, and then participated in bladder nociceptive sensory conduction $(20,22)$. The discharge frequency of $\mathrm{P} 2 \mathrm{X} 3$-mediated bladder afferent nerves was significantly higher than that of normal bladder afferent nerves in an IC animal model (21). In the CYPinduced IC model, increased excitability of the bladder C sensory fibers was also detected (22). In our study, we found that the expression of the $\mathrm{P} 2 \mathrm{X} 3$ receptor in DRG neurons was significantly increased after CYP-induced IC, and an IT of a P2X3 receptor inhibitor significantly inhibited ICinduced overactivity in DRG neurons. Our study suggests that $\mathrm{P} 2 \mathrm{X} 3$ receptors in the DRG may be involved in ICinduced bladder overactivity by regulating the excitability of bladder afferent nerves. Other studies also reported some different signals which could participate in bladder voiding dysfunction and chronic pelvic pain in CYPinduced cystitis except $\mathrm{P} 2 \mathrm{X} 3$ receptors. For instance, Tooke et al. (23) indicated that VEGF overexpression is associated with immature angiogenesis within the urinary bladder wall and bladder afferent nerve sensitization, leading to visceral hyperalgesia and pelvic pain, thus VEGF may be a biomarker for interstitial cystitis/bladder pain syndrome and that targeting VEGF/VEGFR2 signaling may be an effective treatment. Arms et al. (24) found that chemokines/ receptors such as CCL2/CCR2 may also be novel targets with therapeutic potential in the context of urinary bladder inflammation. Therefore, the underlying mechanism of interstitial cystitis/bladder pain is complicated, further study is still required.

\section{Conclusions}

Our study established a CYP-induced IC rat model. This model demonstrated the effect of IC on the bladder voiding function and demonstrated a significant increase in the expression of $\mathrm{P} 2 \mathrm{X} 3$ receptors in IC DRG neurons. The results showed that an IT of a $\mathrm{P} 2 \mathrm{X} 3$ receptor inhibitor significantly improved IC-induced overactivity in the bladder. We hope this study can provide insight into P2X3, which can be considered as a potential biomarker for patients with IC.

\section{Acknowledgments}

We would like to acknowledge the reviewers for their helpful comments on this paper.

Funding: None.

\section{Footnote}

Reporting Checklist: The authors have completed the ARRIVE reporting checklist. Available at https://tau. amegroups.com/article/view/10.21037/tau-22-23/rc

Data Sharing Statement: Available at https://tau.amegroups. com/article/view/10.21037/tau-22-23/dss

Conflicts of Interest: All authors have completed the ICMJE uniform disclosure form (available at https://tau.amegroups. com/article/view/10.21037/tau-22-23/coif). The authors have no conflicts of interest to declare.

Ethical Statement: The authors are accountable for all aspects of the work in ensuring that questions related to the accuracy or integrity of any part of the work are appropriately investigated and resolved. Animal experiments were performed under a project license [No. SCXK (Jin), 2020-0001] granted by the ethics committee of First Affiliated Hospital of Shanxi Medical University, in compliance with guidelines of Shanxi Medical University for the care and use of animals.

Open Access Statement: This is an Open Access article distributed in accordance with the Creative Commons Attribution-NonCommercial-NoDerivs 4.0 International License (CC BY-NC-ND 4.0), which permits the noncommercial replication and distribution of the article with 
the strict proviso that no changes or edits are made and the original work is properly cited (including links to both the formal publication through the relevant DOI and the license). See: https://creativecommons.org/licenses/by-nc-nd/4.0/.

\section{References}

1. Furuta A, Yamamoto T, Igarashi T, et al. Bladder wall injection of mesenchymal stem cells ameliorates bladder inflammation, overactivity, and nociception in a chemically induced interstitial cystitis-like rat model. Int Urogynecol J 2018;29:1615-22.

2. Andersson KE. Bladder activation: afferent mechanisms. Urology 2002;59:43-50.

3. Farmer MA, Huang L, Martucci K, et al. Brain White Matter Abnormalities in Female Interstitial Cystitis/ Bladder Pain Syndrome: A MAPP Network Neuroimaging Study. J Urol 2015;194:118-26.

4. Ryu CM, Yu HY, Lee HY, et al. Longitudinal intravital imaging of transplanted mesenchymal stem cells elucidates their functional integration and therapeutic potency in an animal model of interstitial cystitis/bladder pain syndrome. Theranostics 2018;8:5610-24.

5. Dang K, Lamb K, Cohen M, et al. Cyclophosphamideinduced bladder inflammation sensitizes and enhances P2X receptor function in rat bladder sensory neurons. J Neurophysiol 2008;99:49-59.

6. Yoshimura N, Oguchi T, Yokoyama H, et al. Bladder afferent hyperexcitability in bladder pain syndrome/ interstitial cystitis. Int J Urol 2014;21 Suppl 1:18-25.

7. Andersson KE. Purinergic signalling in the urinary bladder. Auton Neurosci 2015;191:78-81.

8. Malde S, Palmisani S, Al-Kaisy A, et al. Guideline of guidelines: bladder pain syndrome. BJU Int 2018;122:729-43.

9. Mota LC, Barfield C, Hernandez JP, et al. Nonylphenolmediated CYP induction is PXR-dependent: The use of humanized mice and human hepatocytes suggests that hPXR is less sensitive than mouse PXR to nonylphenol treatment. Toxicol Appl Pharmacol 2011;252:259-67.

10. Acevedo R, Parnell PG, Villanueva H, et al. The contribution of hepatic steroid metabolism to serum estradiol and estriol concentrations in nonylphenol treated MMTVneu mice and its potential effects on breast cancer incidence and latency. J Appl Toxicol 2005;25:339-53.

11. Fan ST, Nie SP, Huang XJ, et al. Protective properties of combined fungal polysaccharides from Cordyceps sinensis and Ganoderma atrum on colon immune dysfunction. Int
J Biol Macromol 2018;114:1049-55.

12. Burnstock G. Purinergic signalling in the urinary tract in health and disease. Purinergic Signal 2014;10:103-55.

13. Takezawa K, Kondo M, Nonomura N, et al. Urothelial ATP signaling: what is its role in bladder sensation? Neurourol Urodyn 2017;36:966-72.

14. El-Hamamsy D. Bladder wall injection of mesenchymal stem cells ameliorates bladder inflammation, overactivity and nociception in a chemically induced interstitial cystitis-like rat model. Int Urogynecol J 2019;30:845-6.

15. Sun Y, Chai TC. Augmented extracellular ATP signaling in bladder urothelial cells from patients with interstitial cystitis. Am J Physiol Cell Physiol 2006;290:C27-34.

16. Chen X, Molliver DC, Gebhart GF. The P2Y2 receptor sensitizes mouse bladder sensory neurons and facilitates purinergic currents. J Neurosci 2010;30:2365-72.

17. Dang K, Bielefeldt K, Gebhart GF. Cyclophosphamideinduced cystitis reduces ASIC channel but enhances TRPV1 receptor function in rat bladder sensory neurons. J Neurophysiol 2013;110:408-17.

18. Sano T, Kobayashi T, Negoro H, et al. Intravital imaging of mouse urothelium reveals activation of extracellular signal-regulated kinase by stretch-induced intravesical release of ATP. Physiol Rep 2016;4:e13033.

19. Ueda N, Kondo M, Takezawa K, et al. Intravesical ATP instillation induces urinary frequency because of activation of bladder afferent nerves without inflammatory changes in mice: A promising model for overactive bladder. Biochem Biophys Res Commun 2018;506:498-503.

20. Bayrak O, Erturhan S, Seckiner I, et al. Chemical cystitis developed in experimental animals model: Topical effect of intravesical ozone application to bladder. Urol Ann 2014;6:122-6.

21. Lee YL, Lin KL, Chuang SM, et al. Elucidating Mechanisms of Bladder Repair after Hyaluronan Instillation in Ketamine-Induced Ulcerative Cystitis in Animal Model. Am J Pathol 2017;187:1945-59.

22. Song PH, Chun SY, Chung JW, et al. Comparison of 5 Different Rat Models to Establish a Standard Animal Model for Research Into Interstitial Cystitis. Int Neurourol J 2017;21:163-70.

23. Tooke K, Girard B, Vizzard MA. Functional effects of blocking VEGF/VEGFR2 signaling in the rat urinary bladder in acute and chronic CYP-induced cystitis. Am J Physiol Renal Physiol 2019;317:F43-51. 
24. Arms L, Girard BM, Malley SE, et al. Expression and function of CCL2/CCR2 in rat micturition reflexes and somatic sensitivity with urinary bladder inflammation. Am

Cite this article as: Pang L, Shao J, Wen X, Liu D, Zhang Z, Shuang W. Effect of the neuropathic pain receptor P2X3 on bladder function induced by intraperitoneal injection of cyclophosphamide (CYP) in interstitial cystitis rats. Transl Androl Urol 2022;11(3):304-312. doi: 10.21037/tau-22-23
J Physiol Renal Physiol 2013;305:F111-22.

(English Language Editor: C. Mullens) 